\title{
Uma prática de leitura contemporânea para adolescentes e jovens
}

\author{
A contemporary reading practice for adolescents and young people \\ Una práctica de lectura contemporánea para adolescentes y jóvenes
}

Recebido: 25/01/2021 | Revisado: 31/01/2021 | Aceito: 02/02/2021 | Publicado: 09/02/2021

\author{
Katya Karina Figueiredo Machado \\ ORCID: https://orcid.org/0000-0003-1719-8255 \\ Universidade Federal do Pampa, Brasil \\ katyakarina42@gmail.com \\ Vanderlei Folmer \\ ORCID: https://orcid.org/0000-0001-6940-9080 \\ Universidade Federal do Pampa, Brasil \\ vanderleifolmer@unipampa.edu.br \\ Rodrigo de Souza Balk \\ ORCID: https://orcid.org/0000-0001-5254-6732 \\ Universidade Federal do Pampa, Brasil \\ rodrigobalk@unipampa.edu.br
}

\begin{abstract}
Resumo
Este artigo visa apresentar resultados de uma pesquisa bibliográfica acerca da importância da leitura pelo público adolescente e jovem. Esse estudo objetiva fomentar o incentivo a essa prática, para que os sujeitos compreendam melhor o mundo e a si mesmos, tornando-se mais humanizados e felizes. $\mathrm{Na}$ metodologia foi realizado um levantamento bibliográfico, seguido de consultas a diferentes fontes de leitura. Obteve-se como resultado ideias de diferentes autores que mostram que na leitura literária há um vínculo entre os sujeitos e a aplicação dos direitos humanos, desde que ajam com protagonismo e autonomia. Também, mostra uma análise quanto ao tipo de linguagem destinada ao público jovem, estabelecendo relações de proximidade dele com a leitura, apresentando, dessa forma, algumas sugestões de obras que podem ser lidas pelos adolescentes, cumprindo com a função, não só de divertir, mas de lhes apresentar novas ideias de convivência em sociedade. Além disso, mostra a facilidade com a qual a Internet está ocupando os espaços na vida das pessoas, interagindo de forma invasiva entre adolescentes e jovens, trazendo novidades que encantam, mas que também escravizam; são as adaptações modernas que seduzem, atraem, facilitam, mas exigem muito tempo, espaço e capacitação dos envolvidos. Foi possível concluir que a leitura é um tema muito abordado pelos autores, dada sua importância para o crescimento humano. Espera-se que essas ideias sirvam de inspiração para qualquer pessoa que deseje ser um facilitador para a formação de um mundo mais leitor.
\end{abstract}

Palavras-chave: Público jovem; Leitura; Influência digital; Modernidade; Educação; Ensino.

\begin{abstract}
This article aims to present results of a bibliographic research about the importance of reading by the adolescent and young audience. This study aims to foment the incentive of this practice, so that the subjects better understand the world and themselves, becoming more humanized and happy. In the methodology, a bibliographic survey was carried out, followed by consultations with different reading sources. As a result, ideas were obtained from different authors that show that in literary reading there is a link between subjects and the application of human rights, as long as they act with protagonism and autonomy. It also shows an analysis as to the type of language intended for young audiences, nearness relationships close relations with them with reading, thus presenting some suggestions of works that can be read by teenagers, fulfilling the function, not only of having fun, but to present them with new ideas of living together in society. In addition, it shows the ease with which the Internet is occupying spaces in people's lives, interacting in an invasive way between teenagers and young people, bringing news that delight, but also enslave; they're modern adaptations that seduce, attract, facilitate, but require a lot of time, space and training from those involved. It was possible to conclude that reading is a topic very addressed by the authors, given its importance for human growth. It is hoped that these ideas will serve as inspiration for anyone who wishes to be a facilitator in the formation of a more reader world.
\end{abstract}

Keywords: Young people; Reading; Digital influence; Modernity; Education; Teaching. 


\begin{abstract}
Resumen
Este artículo tiene como objetivo presentar los resultados de una investigación bibliográfica sobre la importancia de la lectura por parte del público adolescente y joven. Este estudio tiene como objetivo incentivar el fomento de esta práctica, para que los sujetos comprendan mejor el mundo y a sí mismos, haciéndose más humanizados y felices. En la metodología se realizó un relevamiento bibliográfico, seguido de consultas con diferentes fuentes de lectura. Como resultado, se obtuvieron ideas de diferentes autores que demuestran que en la lectura literaria existe un vínculo entre los sujetos y la aplicación de los derechos humanos, siempre que actúen con protagonismo y autonomía. También muestra un análisis en cuanto al tipo de lenguaje destinado al público joven, estableciendo estrechas relaciones con ellos con la lectura, presentando así algunas sugerencias de obras que pueden ser leídas por adolescentes, cumpliendo con la función, no solo de divertirse, sino presentarles nuevas ideas de convivencia en sociedad. Además, muestra la facilidad con la que Internet está ocupando espacios en la vida de las personas, interactuando de forma invasiva entre adolescentes y jóvenes, aportando novedades que deleitan, pero también esclavizan; son las adaptaciones modernas las que seducen, atraen, facilitan, pero exigen mucho tiempo, espacio y formación a los implicados. Se pudo concluir que la lectura es un tema muy abordado por los autores, dada su importancia para el crecimiento humano. Se espera que estas ideas sirvan de inspiración para todo aquel que desee ser un facilitador en la formación de un mundo más lector.
\end{abstract}

Palabras clave: Gente joven; Lectura; Influencia digital; Modernidad; Educación; Ensenãnza.

\title{
1. Introdução
}

A educação brasileira, em Brasil (2017), apresenta a Base Nacional Comum Curricular (BNCC) priorizando a leitura no contexto escolar. Dessa forma, mostra interesse em que mais pessoas leiam, com intenção de leitura, não apenas para seu próprio deleite, mas também, para adquirirem mais experiências e enriquecerem sua identidade, seus hábitos, sua formação individual e a partir daí, favorecer o crescimento cultural e social da nossa nação. A BNCC aposta na literatura como uma fonte inesgotável de saber, gestando novos olhares e novas perspectivas, para que o conhecimento se concretize na prática e que seja um direito de todos. Muitos são os envolvidos nesse cenário. Não apenas professores, mas também adultos que convivem, que criam, que alimentam e educam nas suas casas, que são os pais. Esses são de elementar importância para que de fato adolescentes e jovens não esmoreçam durante o percurso da sua caminhada rumo ao prazer de ler para melhor conviver.

Adolescentes e jovens são o público ideal para que este artigo tenha fundamento, pois são esses indivíduos que estão transitórios numa fase quase adulta. Daí a importância de conhecermos mais sobre do que gostam, como reagem diante de leituras mais emotivas ou mais turbulentas. Qual o real espaço que a leitura tem em suas vidas. Intenciona-se gerar uma sensação de incompletude, para que percebam que por estarem mudando, são as pessoas certas para fazerem a diferença. Porém, isso só ocorrerá se estiverem mobilizados e atraídos para uma leitura na qual se identifiquem, que espelhem suas dúvidas, ansiedades e sonhos.

Muitos adolescentes e jovens precisam de incentivo, não formaram ainda uma estrutura forte de autoestima. Daí a sensibilidade do adulto em lhes mostrar alguns nortes, para que não foquem sua atenção apenas no que a Internet oferece. Sentir-se ousado, irreverente, autêntico, podem ser algumas características desse público, então, melhor cuidar para que usem desses mecanismos para uma promoção eficaz de si mesmos e que sejam felizes com isso.

$\mathrm{Na}$ sociedade contemporânea, há uma grande relutância dos jovens em ler e uma enorme dificuldade dos profissionais da educação e familiares em encontrar alternativas para sanar esse problema. Dessa forma, este artigo se justifica pela pesquisa realizada, trazendo assuntos diversificados e colaborativos com a necessidade 
encontrada. O objetivo principal deste artigo é fomentar o incentivo à prática leitora e mostrar o bem que a leitura pode proporcionar aos indivíduos.

\section{Metodologia}

A leitura é essencial na vida das pessoas, "trata-se de uma prática emancipadora, pois é capaz de libertar o homem da ignorância" (Silva \& Fernandes, 2020a, p. 03). Portanto, para a produção do presente artigo, com o intuito de fortalecer e resgatar ideias sobre a importância da leitura para adolescentes e jovens, foi feita uma revisão sistemática sobre o assunto, em que se realizou um levantamento bibliográfico, seguido de consultas a fontes de leitura, artigos, sites disponíveis na Internet e, por isso, é uma pesquisa de abordagem qualitativa porque "os métodos qualitativos são aqueles nos quais é importante a interpretação por parte do pesquisador com suas opiniões sobre o fenômeno em estudo" (Pereira et. al, 2018, p. 67).

O presente estudo pode ser classificado quanto a sua natureza como uma pesquisa básica, porque não teve aplicação prática entre os indivíduos estudados. O procedimento técnico utilizado na pesquisa foi o bibliográfico, com método indutivo, pois parte de dados escritos pelos diferentes autores para que conclusões gerais sobre o assunto fossem tiradas e discorridas no texto. Para Silva \& Fernandes (2020b, p. 04) "a pesquisa bibliográfica, ou revisão da literatura, é um tipo de pesquisa que tem como objetivo conhecer, analisar e levantar as principais contribuições teóricas existentes a respeito de um determinado tema", pois acredita ser um primeiro passo importante para os estudos que ainda acontecerão pelos pesquisadores.

As fontes utilizadas contaram com as contribuições de Barthes (2002); Brait (2005); Farias (2018, 2019); Filho (2019); Flanagan (2011); Iser (1999); Silva; Fernandes (2020), dentre outros, com a intenção de se obter um diálogo entre os autores, a fim de tirar os principais conceitos sobre o tema, trazendo uma visão mais clara e contundente para o público leitor. A análise nas bases legais como o Estatuto da Criança e do Adolescente, Base Nacional Comum Curricular (2017), teve por finalidade apontar argumentos fundamentados por esses documentos orientadores na educação, para trazer a real relevância do estudo.

\section{Resultados e Discussão}

Para Silva e Fernandes (2020b, p. 06) os indivíduos que manifestam interesse e hábito leitor "são necessárias às relações sociais do planeta”, porque esse é um dos meios essenciais para que ele tenha contato com diferentes culturas e, por conta disso, amplie sua visão de mundo, colaborando com a própria cultura do espaço em que ele integra. Para a compreensão da temática: leitura, na fase adolescente e jovem, a partir de estudos realizados nas diferentes fontes, dividiu-se o estudo em subtítulos para melhor apresentar as discussões realizadas. São eles: Leitura e educação; Leitura na adolescência: o que o jovem busca na leitura; Leitura na adolescência: A Influência da Internet. Assim, a partir do estudo feito e arrazoado no texto, espera-se gerar resultados positivos na influência leitora de educadores, família, alunos e escola.

\subsection{Leitura e educação}

A Base Nacional Comum Curricular - BNCC, Brasil (2017), apresenta o componente curricular Língua Portuguesa, como o carro condutor para que estudantes ampliem seus espaços significativos e de letramento, de forma a contribuírem na sociedade a partir das diferentes linguagens. Para Marroquim e Silva (2020, p. 03), "nas 
sociedades contemporâneas, textos não são apenas verbais: há uma variedade em sua composição, tendo aqueles que articulam o verbal, o visual, o gestual e o sonoro, o que se denomina multimodalidade de linguagens". A BNCC traz em um de seus eixos: a leitura, discorrendo sobre "textos escritos, orais e multissemióticos" terem a finalidade de trazer:

[...] fruição estética de textos e obras literárias; pesquisa e embasamento de trabalhos escolares e acadêmicos; realização de procedimentos; conhecimento, discussão e debate sobre temas sociais relevantes; sustentar a reivindicação de algo no contexto de atuação na vida pública; ter mais conhecimento que permita o desenvolvimento de projetos pessoais, dentre outras possibilidades (Brasil, 2017, p. 69).

Apresenta nas competências específicas de Língua Portuguesa 3, 8 e 9 (Brasil, 2017, p. 85) a importância da leitura de textos ou de livros, com o objetivo não apenas do entretenimento, mas da formação individual, reconhecendo na literatura uma possível nova realidade. Percebendo ali o espaço em que a leitura tenha função social, que se manifeste nas diferentes opiniões, mexendo nas estruturas, reinventando jeitos de agir e de viver em harmonia e de forma humanizada. Firma esse propósito no campo artístico - literário, quando em uma das habilidades reitera:

Inferir a presença de valores sociais, culturais e humanos e de diferentes visões de mundo, em textos literários, reconhecendo nesses textos formas de estabelecer múltiplos olhares sobre as identidades, sociedades e culturas e considerando a autoria e o contexto social e histórico de sua produção (Brasil, 2017, p. 155).

Dada a relevância do assunto, Farias (2018, p.178) corrobora essa ideia e afirma que "a leitura literária deve se oferecer aos adolescentes e aos jovens como repertório para compreender o mundo e, também, para dizêlo e indagá-lo". Dessa forma, Silva \& Martha (2017) incorporam a ideia das mudanças sociais que aparecem no decorrer dos anos, reafirmando que não há indivíduos mais suscetíveis a aceitar as mudanças que os jovens. Falam ainda, que essas mudanças, agem e modificam diretamente os aspectos da vida deles, como seu lazer e as formas como se relacionam cotidianamente, principalmente quando tratam das novidades do mundo virtual. Costurando essa ideia, entende-se que:

É na perspectiva do trabalho educativo escolar que considera a historicidade dos sujeitos e a produção e circulação social do conhecimento que se insere a reflexão sobre o sentido da experiência estéticoliterária e do conhecimento crítico das ciências humanas e sociais na formação de adolescentes e jovens (Farias, 2019, p. 13).

A importância de como a leitura é gestada na escola, articulada com o despertar do prazer, construindo verdadeiros sentidos, o que para Turci e Pacífico (2019, p.133) autoriza "os sujeitos-alunos a dizerem e a ocuparem a posição discursiva de sujeito que pode argumentar e ser autor do seu dizer”. Para Silva e Fernandes (2020a, p. 08) "essa nova realidade traz a necessidade de refletir, a respeito do papel do aluno nos processos de ensino-aprendizagem, conduzindo para uma educação na qual o aluno ocupe posição mais central e menos secundária”. Justamente pela necessidade de falar ou escrever com propriedade, o que esse sujeito poderá dar e sentir com relação aos outros. Posicionar-se, ser alguém! É a literatura interligada aos direitos humanos. Isso é 
referendado por Guerino e Carlesso (2019, p. 03) quando afirmam que "a transmissão do conhecimento se apoia no exercício contínuo da leitura. Lê-se para tudo ou quase tudo".

A sociedade tem pouco acesso à arte e literatura e, por ajudar a fluir ideias e ideologias, torna-se capaz de humanizar as pessoas, para que tenham condições de se colocar como agente de mudanças, árduo estimulador e batalhador pela justiça social. Capaz de não apenas estar no mundo, mas fazer parte dele efetivamente. Para Guerino e Carlesso (2019, p. 08), "as relações homem-mundo, bem como sua ação transformadora, geram a história, produzem os bens materiais, as intuições, as ideias e concepções". Farias (2019) discorre acerca dessa ideia quando diz que a leitura literária pode ser usada como instrumento para que adolescentes e jovens se analisem, conheçam-se e a partir daí, compreendam o mundo, praticando a alteridade, entendendo num exercício diário que somos diferentes e, nem por isso, menos importantes. Ressalta ainda que educadores enfatizam apenas sobre a história da literatura em suas aulas, no Ensino Médio, "esvaziando o valor intrínseco da leitura de romances, contos, poemas e textos dramatúrgicos, cuja leitura pode ajudar a entender quem somos e que mundo é esse em que vivemos" (Farias, 2019, p. 17).

Um fator de grande valor é expresso por Turci e Pacífico (2019) quando consideram que da argumentação brota o protagonismo. São pequenas centelhas que ao serem espalhadas ao vento, podem causar estragos irreparáveis na hipocrisia, desumanidade, desestímulo, desigualdade; dando espaço para gerar vida, posicionamentos que interferirão no crescimento pessoal e social. Daí a importância de "direcionar nossos olhares para os saberes que circulam na escola, para o ensino que nela se pratica e para os sujeitos que nela (se) significam, proporcionando papel de estaque ao trabalho com a argumentação e a autoria" (Turci \& Pacífico, 2019, p. 129).

\subsection{Leitura na adolescência: o que o jovem busca na leitura}

O jovem leitor, segundo Santos; Carvalho e Ferreira (2017, p. 250), busca na literatura o entretenimento, influenciando-se pelos momentos de comoção, encontros de amor, situações de afeto ou de comicidade vivenciados pelos personagens, aprendendo com eles. Compreendem que as diferentes situações não são alheias às vivências e convivências humanas, que há soluções pra tudo, "também aprendem com eles, principalmente a não desistirem de querer viver quando surgem momentos trágicos nas suas vidas". Essa ideia também é apresentada por Marroquim \& Silva (2020, p. 03), quando discorrem que qualquer tipo de leitura é importante e inclui Histórias em quadrinhos como aliadas aos jornais e revistas em circulação, porque "representam um dos mais difundidos meios de comunicação de massa, alcançando, por meio de suas características, uma influência considerável na formação de leitor". Haja visto que traz na sua essência um misto de afetos e desafetos dos personagens que revelam ações normais do cotidiano humano.

Dessa forma, pode-se dizer que o texto literário reflete no jovem leitor a sua própria imagem e o leva "a se questionar sobre sua existência" (Santos et al., 2017, p. 245) e, daí a sua importância, porque auxilia no reconhecimento e construção de identidades. $\mathrm{O}$ autor afirma ainda que no ato de ler, a pessoa sente e vivencia as atividades humanas, podendo discernir entre o que está certo ou o que está errado. Quanto maior for o contato do público jovem com a literatura, maior será seu desdobramento, primeiro como ser humano, segundo como agente de mudanças. Para Marroquim e Silva (2020, p. 03), "cabe ao professor utilizar novas formas que propiciem a inserção do educando no universo literário, com o uso de diferentes gêneros, tipos e suportes textuais", fazendo com que compreendam o que está escrito, muito além das palavras, colocando em prática na 
própria vida, fazendo a diferença no mundo. Isso é incentivado por Silva \& Fernandes (2020a, p. 05), quando dizem que é importante "valorizar a capacidade interativa do aluno, enxergando-o como um sujeito social, advindo de um meio cultural e carregado de conhecimento de mundo, são ações que, certamente, contribuem para a aprendizagem e para formação de leitores".

Umas das autoras brasileiras para adolescentes atualmente é Thalita Rebouças. Em entrevista à Revista Isto é Online, ao ser abordada por adolescentes que a agradeciam pelo livro Fala sério, mãe!, declara "que adolescentes e pré-adolescentes estavam muito carentes de se reconhecer nas páginas dos livros”(Diniz, 2018). Nesse momento ela percebe a qual público leitor seus trabalhos iriam fazer referência ou seriam destinados. Quanto menos rebuscada for a linguagem e mais considerar os problemas habituais, mais atraente se tornará a leitura para os adolescentes. Não deve haver a preocupação em inovar na forma de escrever ou colocar palavras pouco usadas na linguagem informal, como Santos et al. (2017, p. 249) bem salienta "nessas narrativas há uma economia vocabular, usa-se mais uma linguagem do cotidiano e, principalmente, a do mundo jovem”. Essa ideia é reverberada por Rebouças ao retratar situações de bullying em seu livro lançado em 2017, Confissões de uma garota popular, linda e (secretamente) infeliz. Ao ser entrevistada diz que o texto fala sobre uma menina que pratica bullying e quer "mostrar porque alguém maltrata os outros. De onde vem essa crueldade?" (Diniz, 2018). Reforça o posicionamento de que a realidade transcrita para a ficção é capaz de gestar o gosto pela leitura.

É necessário, ainda, esclarecer que, conforme Santos et al. (2017), a utilização de uma linguagem menos planejada, menos monitorada, empregando uma gramática natural incorporada no contexto, não diminui a intenção do texto e não impede que o leitor faça suas interpretações e seja capaz de manifestar suas inquietudes e perguntas adequadas ao contexto. Turci \& Pacífico (2019) aduzem que com frequência as escolas silenciam as vozes dos alunos e que muitas vezes isso passa despercebido, dada a naturalidade em que ocorre. Reafirmam da importância da ação argumentativa para que o aluno tenha participação atuante na sociedade.

Ao analisarmos outras obras pertinentes a esta faixa etária, dos 12 aos 18 anos, considerando o Estatuto da Criança e do Adolescente, percebemos que "as leituras dialogam entre si e movimentam o repertório do leitor" (Farias, 2018, p. 183). Muitos textos contextualizam momentos históricos em personagens completamente fictícios, é o caso do livro "A Lua Castelhana”, de Maria da Graça Rodrigues, escritora Uruguaianense, cidade do interior do Rio Grande do Sul. Nessa obra ela retrata a saga de um jogador de futebol Uruguaio, nascido e criado em Bella Unión, cidade do interior do Uruguai, fronteira com o Brasil, que, ao ter seu talento descoberto, vai morar na capital porto alegrense, capital do estado do RS, joga num grande time, torna-se famoso e tem um envolvimento romântico com uma jornalista. Porém, em visita a sua família, a personagem Juan Rios Ortega traz sua esposa Ana Lúcia Silva, que resolve entrevistar um político brasileiro exilado no Uruguai. Retornando ao Brasil, ela é perseguida e sequestrada grávida, tempos árduos de ditadura militar. Some. Nunca mais aparece. Porém, a autora abrilhanta a história com um final extraordinariamente encantador e surpreendente. Ao ser entrevistada sobre seu livro que envolve futebol e política diz que "política e futebol são assuntos apaixonantes, não tem como ficar alheio a eles. Mas meu romance aborda o drama humano de um jogador de futebol e não o esporte em si” (Lopes, 2012). Fala ainda que quer mostrar como foco do seu romance quais foram os prejuízos e sequelas deixadas pelo período da ditadura militar.

Para o adolescente da fronteira do Rio Grande do Sul, ao ler em uma obra, palavras próprias da região da campanha, do seu ambiente, com uma intensa variedade linguística regional, sente-se tocado, extasiado. Isso é intensificado por Santos et al. (2017, p. 243) ao dizer: "sabemos, portanto, que a literatura, de maneira suscinta, 
refere-se à produção artística movida pelo uso da linguagem. Surge quando o sujeito se deixa ser tocado pelo mundo interior e exterior e tenta transformar as sensações que surgem em palavras". Quanto ao prazer de ler, Barthes (2002, p. 19) menciona sobre os livros que "não posso ser levado a dizer: este é bom, aquele é mau. Não há quadro de honra, não há crítica, pois esta implica sempre um objetivo tático, um uso social e muitas vezes uma cobertura imaginária".

A série Rangers, Ordem dos Arqueiros, de John Flanagan, traz ao público adolescente ótimas premissas de lealdade, amizade, coragem e companheirismo. Na obra, Halt em perigo, num pequeno trecho podemos detectar a juventude dos personagens, bem como suas nobres atitudes de cumplicidade:

Mais uma vez, como tinha feito vários meses antes, olhou o arqueiro a sua frente e se surpreendeu com a força e solidez de caráter de alguém tão jovem. Horace se aproximou do amigo e pôs a grande mão no ombro de will. Malcolm viu os nós dos dedos ficarem brancos pela pressão que a mão exercia, fazendo Will saber que não estava só. (Flanagan, 2011, p. 255).

Qual adolescente ou jovem não gostaria de ter presente em sua vida um amigo que o apoie, prestigie e se compadeça com ele diante de algum infortúnio? Esse é o sentido da leitura que se quer resgatar. "Além de ler histórias, os adolescentes e jovens devem ser levados a compreender a literatura como produção humana e histórica, que traz em si marcas objetivas e subjetivas, visões de mundo e lugares de fala" (Farias, 2018, p. 191). Isso é fortemente enfatizado por Barthes (2002, p. 45) quando diz "o livro faz o sentido, o sentido faz a vida".

A partir da leitura precisamos sair transformados. Para Iser (1999, p. 51) o ato de experimentar um livro deve exercer influência nas nossas experiências. "Ela não pode permanecer a mesma pelo fato de nossa presença no texto não ser mero reconhecimento do que já sabemos". O autor relata sobre a interação entre as experiências individuais e as adquiridas pelo meio da leitura. Quanto a isso, Brait (2005, p. 164) faz uma ressalva ao mencionar sobre a interação, dando o exemplo de uma feira, espaço em que pessoas vendem e propagandeiam os produtos a serem comercializados. Aponta a presença de outros personagens que ali estão, interagindo com o público, ou por mágicas, ou pelo canto ou ainda a poesia. Ainda, para Brait (2005, p. 164), a "feira é um espaço semiótico rico de acontecimentos inusitados e simultâneos. [...] Isso tem a ver com uso da linguagem em esferas específicas de interação". É preciso resgatar os cabos de conexão entre o leitor e a leitura, fazendo com que interajam e produzam significados.

\subsection{Leitura na adolescência: a influência da internet}

É difícil concorrer com a Internet. Canclin (2008, p. 23) como citado em Machiavelli (2017, p.04) afirma que "ao mesmo tempo, a escola vê se reduzir sua influência: primeiro a mídia de massas e, recentemente, a comunicação digital e eletrônica multiplicaram os espaços e circuitos de acesso aos saberes e à formação cultural". O jovem ou adolescente se vê fascinado pelo mundo virtual, os jogos, as séries de tv. Marastoni (2015, p. 90) acrescenta que a Internet "favorece a dispersão de notícias em curto espaço de tempo". Isso induz ainda mais aos jovens à imersão na nova realidade. Eles acompanham youtubers famosos e sonham em se tornarem um deles, pela fama, sucesso e dinheiro que ganham. Seguem Djs famosos, que usam como recursos músicas eletrônicas, e que são tão apreciados pelo público jovem que viram personagens de jogos, atraindo mais atenção, mais fama, mais dinheiro, numa corrente interminável de poder e consumo. Esses mesmos jovens, pouco se sentem motivados a ler o livro impresso. Brait (2005, p. 164) adverte para os gêneros discursivos que estavam 
sendo usados para a comunicação visual nas grandes cidades, alertando pela utilização do "rádio, televisão e mídia digital para reproduzir os gêneros básicos da programação como jornalismo, publicidade, videoclipe, charges, slogan, gingles e vinhetas".

São tantos avanços tecnológicos, Saccol et al. (2010) como citado em Santos, Barbosa, Silva \& Barbosa (2019, p. 01) falam em "aprendizagem com mobilidade, caracterizada pelo uso em qualquer lugar de recursos tecnológicos para acesso, produção e compartilhamento de conhecimento". A modernidade está marcada por suportes e plataformas imediatistas, tudo tão prático que se torna imprescindível. Silva \& Fernandes (2020a, p. 03) reafirmam que "a clientela atual da escola é composta por indivíduos imersos em um mundo digital, rodeados por meios de comunicação instantâneos. Este novo cenário exige da escola, cada vez mais, uma postura inovadora que vise despertar os alunos para a leitura". O adolescente se acostumou à informação rápida, a sinopse de um livro num clique. Filho (2019, p. 216) ressalta que a modernidade aliada à tecnologia "apresenta ao jovem nas telas de seus aparelhos eletrônicos facilmente acessados por um simples deslizar dos dedos nas telas, visto que essas mãos ainda não possuem a segurança da idade adulta”. É preciso um olhar sensível da família e da escola de não acharem que esses adolescentes e jovens já tem a maturidade necessária para terem acesso livre ao que a Internet proporciona. Ainda que estejamos falando em jovens da geração $\mathrm{Z}$, que quando chegaram a este mundo, já tinham celulares e Internet como realidade do cotidiano. Kämpf (2011) na Revista ComCiência versão online, descreve essa geração da seguinte forma:

Um adolescente de classe média, hoje na faixa dos 15 anos de idade, nasceu num período em que o Google e a internet já faziam parte da vida cotidiana de muitas pessoas do seu universo de convívio, tanto no aspecto social como educacional. Muito provavelmente, a Wikipedia é a única enciclopédia que ele conhece e usa para fazer as pesquisas da escola e, com mais certeza ainda, esse adolescente maneja com destreza qualquer tocador de mp3, celular, smartphone, tablet ou leitor de e-book e já tentou ensinar seus professores, pais ou avós a usar o controle remoto da TV de LED ou mesmo a criar um perfil no Facebook (Kämpf, 2011, p. 01).

Iniciamos uma década diferenciada, imersos na pandemia da Covid-19, que modificará para sempre as posturas e comportamentos de todos. De uma hora pra outra fizemos da tecnologia nosso único meio orientador, fazendo uso "de uma cultura digital que usa a tecnologia para comunicação, entretenimento e aprendizagem" (Santos et al., 2019, p. 01).

Professores, crianças, adolescentes e jovens se reconstruíram a cada dia em prol da educação. O que antes era apenas um instrumento, agora é o instrumento. Para Ramos \& Viallaça (2019) como citado em Santos et al. (2019) existem muitos aplicativos na Web que podem facilitar a produção escrita, imergindo os alunos em diferentes gêneros textuais. Para isso o professor precisaria saber orientar e, para tanto, precisa estar atento, como professor pesquisador, buscando primeiro ele próprio aprender, para só depois poder passar ensinamentos e orientações.

[...] a educação que desejamos hoje tem que surpreender, cativar, conquistar os estudantes a todo momento. A educação precisa encantar, entusiasmar, seduzir, apontar possibilidades e realizar novos conhecimentos e práticas. O conhecimento se constrói a partir de constantes desafios, de atividades significativas, que excitem a curiosidade, a imaginação e a criatividade (Moran, 2007, p. 167 como citado em Marastoni, 2015, p. 87). 
Então, de uma hora para outra professores viraram youtubers e quem sabe quantos terminaram o ano de 2020 com blogs ou canais no Youtube, postando suas vídeos-aulas? Silva e Martha (2017, p. 06) acreditam "que o suporte textual blog, sendo um dos mais presentes na vida do jovem, como consideramos anteriormente, pode e deve ser uma ferramenta utilizada para sua formação como leitor crítico e competente". Esse recurso já foi bastante utilizado, favorecendo recomendações de livros literários, dando espaço para a interação do público leitor. Mas, como tudo é transitório, o Youtube ganha força. Com ele, surgem os vídeos, os youtubers, e com eles mais dinamicidade na leitura, visto que no lugar de ler as sugestões dos livros, agora o indivíduo ouve. Não interage, mas dá o seu like.

Em função disso, algumas pessoas resolveram aderir à tendência do momento. São os booktubers, pessoas que gostam muito de ler e criam canais na Internet para contar a quem quiser ouvir, as histórias lidas, expondo opiniões e sentimentos gerados a partir da leitura. Envolvem o público ouvinte por contextualizarem obras já bem antigas, escritas em outras épocas, dando ideias de aspectos que motivaram os escritores que lá fizeram sucesso, justamente por escreverem para um público específico, passando aos leitores da época determinadas normas e atitudes que seriam convenientes para uma sociedade regrada e que tinha posses. Machiavelli (2017) discorre sobre a Internet vir ganhando espaço e abrindo um leque de possibilidades quanto ao acesso a diferentes tipos de leituras e atividades. Já Silva e Martha (2017) destacam que deste formato digital, surgem outros gêneros textuais muito utilizados atualmente, como e-mails, chats, com seus padrões linguísticos particulares, que só são entendidos por aqueles que o acessam com grande frequência. Surge um novo vocabulário, palavras abreviadas, entendidas pelos adolescentes e jovens que tão tem o menor prazer em desvendar seus códigos.

Machiavelli (2017, p. 15) salienta quanto aos adolescentes que "mesmo que a frequência do livro digital em si não seja percebida, a leitura nas redes sociais e o contato que eles têm com autores e outros livros, com livrarias e editoras, já demonstra uma mudança nas relações de compra e consumo”. Filho (2019, p. 212) enfatiza o surgimento do leitor ubíquo, sendo o leitor que vive imerso nas tecnologias, recebendo e enviando muitas mensagens, realizando-as quase que ao mesmo tempo, que está "tão imerso numa cadeia de comunicação que nem sempre age como sujeito consciente". Mas, ninguém pode negar que "os jogos e a internet trazem elementos que potencializam um processo de aprendizagem mais significativo" (Santos et al., 2019, p. 01).

A leitura feita na adolescência, para Machiavelli (2017) segue o crescimento da pessoa e a sua passagem de uma fase da vida para a outra. É a mudança da infância para a adolescência, seguindo transformações biológicas e psicológicas dessa pessoa. As práticas de uma fase são diferentes na outra. Filho (2019, p. 209) corrobora essa ideia dizendo que existem várias designações para essa transição, que "há a categorização por faixa etária, mais próxima do termo 'puberdade' utilizado pelas Ciências da Saúde, que se refere ao período de transformações físicas no corpo do indivíduo no seu processo de amadurecimento". Farias (2019, p. 14) contribui com essa ideia quando diz que a adolescência precisa ser contemplada sob um forte ângulo, não sendo apenas uma superação da infância para passar à vida adulta, mas que traz no conjunto, desde as mudanças apresentadas no corpo, a própria descoberta da sexualidade, mas também, "nas maneiras de relacionamento com pessoas e espaços, na experimentação e limites e contestação de autoridades, nas emoções e sentimentos e, também, em planejamentos de futuro". Farias (2019) ainda salienta que já é coisa do passado dizer apenas que adolescentes são naturalmente rebeldes e irresponsáveis, por isso ter se tornado uma ideologia pouco construtiva, pois desconstrói a ideia de autonomia que pode ser fator determinante na vida do jovem. 
Muitas mudanças ocorrem até mesmo nas estruturas do livro, que segundo Machiavelli (2017, p. 03) "continham mais imagens e eram mais livres, muitas vezes lidas pelos pais ou professores, ou feitas na própria escola". Temos um indivíduo contextualizado pelo século XXI. Quem são os adolescentes de hoje, com o que se preocupam e o que realmente esperam da escola? Quantos deles já tiveram acesso a um e-book ou a um e-reader, leitores de livros digitais? Filho (2019, p. 213) questiona, mediante tanta tecnologia, "qual o papel da literatura nesse contexto de Smartphones, tablets e laptops, universo onde a informação tornou-se protagonista desse universo tecnológico e consumista?". Quantos jovens se interessariam por esses formatos tecnológicos e não teriam condições financeiras para adquiri-los. Machiavelli (2017, p. 14) relata que quanto a ação de formatos e dispositivos nem todos os adolescentes "sabem de todas as possibilidades, e este ponto pode ser importante para reconhecer o motivo de eles não se sentirem tão à vontade com este suporte". Isso exige capacitação e comprometimento, nem todos conseguem aprender, por não disponibilizarem dos meios para isso.

Muitos adolescentes e jovens vivem de forma precária, pertencem ao grupo da exclusão digital, leem quando a escola fornece o material impresso e tem sorte quando na família isso é prioridade. Infelizmente temos três grupos de adolescentes bem formados e construídos pela sociedade discriminatória e excludente em que vivemos. Aqueles que não leem por preguiça, por ter acesso exagerado, liberdade excessiva, espaços desnecessários de diálogo, muita conversa e pouca autoridade familiar. Aqueles que leem por curiosidade, porque a escola oferece, porque planejam um futuro, por querem saber se organizar para uma vida profissional não tão distante agora. Aqueles que nada leem, por falta de incentivo familiar, por desgosto ou falta de esperança na vida.

Adolescentes e jovens vivem um período de transição e isso cria sentidos e significados na escola, conforme Farias (2019, p.20):

O que pode ser tomado como específico nesse período e ressignificado no ambiente escolar são as turbulências, algumas explícitas e traduzidas em comportamentos rebeldes, outras ensimesmadas e silenciosas, mas não menos significativas, aliadas à angústia e à pressão de construção de projetos de vida, de preparação para o mercado de trabalho e, para alguns, para o ingresso no ensino superior (Farias, 2019, p. 20).

Deixar de ser criança requer muito compromisso. A ilusão acaba e dá espaço para novos empreendimentos e exigências de um mercado de trabalho pouco facilitador, muito competitivo, com pouca oferta de empregos e salários muito baixos. Muitas empresas estão evitando custos extras, por perceberem que seus funcionários podem trabalhar de casa, por Home Office, em grandes cidades há uma adequação até mesmo em função do fluxo do trânsito.

$\mathrm{Na}$ verdade, com a inteligência artificial, muitas profissões estarão com os dias contados, os cidadãos precisarão estar conectados para não ficarem ainda mais desempregados. Já somos despreparados para as inovações que estão aí. Turcie Pacífico (2019, p. 124) argumentam que ao compreendermos "a linguagem como forma de interação e de constituição do sujeito, acreditamos que esse vínculo com o ambiente virtual também influencia essa constituição". Ao nos ambientarmos com a praticidade do mundo virtual, estaremos sempre atentos e curiosos por novas adequações, sugestões e processos criativos de construção da leitura. O que Silva e Martha (2017, p. 04) mencionam ao dizer que "Não seria diferente com a literatura que, de certa forma, teve que se inserir neste ciberespaço, buscando sua sobrevivência, mas, principalmente, um meio de conquistar mais 
leitores". O maior desejo é a formação de mais leitores, pessoas que desejem interagir no mundo letrado e ao mesmo tempo tragam contribuições para a sociedade.

\section{Considerações Finais}

Esta revisão bibliográfica permitiu concluir que o tema abordado nesse artigo é de real importância e muito atual. É um assunto que vem sendo tratado ao longo do tempo para respaldar escola, educadores e familiares nos pilares essenciais da leitura e da importância que a mesma traz para o crescimento emocional, cultural e cognitivo dos povos. Assunto este que instiga a necessidade de conhecimento aos indivíduos, para que se enraízem no desenvolvimento eficaz e digno da sociedade. Uma luta constante com os meios de comunicação e tecnológicos, para que adolescentes e jovens percebam o quanto podem ser colaborativos e promotores de mudança.

As reflexões apresentadas neste texto inferem ao público leitor o melhor ideal de leitura para uma sociedade contemporânea. Indivíduos que vivem a era da tecnologia e que vivem em função dela, buscando seguidores, pedindo curtidas e likes, tendo um acesso ilimitado de informações, na praticidade para fazer tudo em menos tempo. Mas, também, deixa rastros de uma geração que pode anular a sua criatividade e autonomia, dependendo de qual uso faz desses meios. Os adolescentes e jovens são o grande alvo da mídia, justamente por estarem em um período transitório da infância para a vida adulta. É preciso estar atento para não alimentarmos uma cultura de imediatismo e acomodação. Às vezes, por achar que tudo é fácil, ao encontrar obstáculos, o indivíduo pode passar por períodos de frustração. Então, entramos na importância da leitura literária, que ajuda muito na transmissão de ideias vivenciadas pelos personagens que sugerem a superação desses problemas. Importante reconhecer na leitura uma ressignificação da própria vida.

Muitas pesquisas são encontradas falando sobre crianças e a leitura na infância. Mas sobre o público jovem há muito ainda a ser descoberto. Daí a eficácia do trabalho apresentado neste artigo, a quem se interessar ou trabalhar com essas pessoas em fase de crescimento e amadurecimento, para continuarmos uma linha de estudo e aprimoramento. O que queremos? Pessoas com outros ideais de vida, buscando por novas vivências, mais proativas, protagonistas e formadoras de opinião. Precisamos disso para movimentar a sociedade e transformar a realidade com qualidade. De uma forma planejada e harmoniosa discorremos sobre esse tema neste artigo, que apresenta oportunidades de pesquisa no campo da leitura, regatando-a como um item fundamental para familiares e educadores que desejam agir de forma diferente com adolescentes e jovens para que estes vejam a beleza e o prazer que a leitura pode proporcionar.

Para trabalhos futuros, pretende-se fazer uma pesquisa com coleta de dados a partir de questionários e entrevistas entre os personagens desse artigo, podendo reproduzir suas opiniões e sugestões que colaborarão para pesquisas posteriores, podendo associar às teorias resgatadas nessa pesquisa bibliográfica. Sabe-se que quando tratamos de leitura, o assunto não se esgota, portanto sempre é preciso realizar pesquisas e estudos para continuar aprimorando as ideias e contribuindo com uma educação de qualidade para todos.

\section{Referências}

Barthes, R. (2002). O prazer do texto. Versão brasileira da editora. (3a ed.), Editora Perspectiva S.A. 
Brasil. (1990). Estatuto da Criança e do Adolescente. Câmara dos Deputados, LEI No 8.069, de 13 de julho de 1990. DOU de 16/07/1990 ECA. Brasília, DF.

Brasil. (2017). Ministério da Educação. Secretaria da Educação Básica. Base nacional comum curricular. Brasília, DF. http://basenacionalcomum.mec.gov.br/\#/site/inicio.

Diniz, P. (2018). Thalita Rebouças - escritora - O humor nos faz pensar sem nos darmos conta. Revista Isto é, edição 2642, no 2538. https://istoe.com.br/o-humor-nos-faz-pensar-sem-nos-darmos-conta/.

Farias, F. R. (2018). A educação literária de adolescentes e jovens no contexto da biblioteca escolar. Revista Letras Raras, 7(03). http://revistas.ufcg.edu.br/ch/index.php/RLR/article/view/1211.

Farias, F. R. (2019). A educação literária na formação de adolescentes e jovens. Revista Exitus, 9(5), 11.

Filho, J. N. G. (2019). Adolescência, literatura e cultura hipermidiática. Revista Miscelânea, 26. http://seer.assis.unesp.br/index.php/miscelanea/article/view/1447.

Flanagan, J. (2011). Rangers - Ordem dos Arqueiros 09 - Halt em Perigo. Versão brasileira da editora. Editora Fundamento Educacional Ltda.

Guerino, S. L. C. \& Carlesso, J. P. P. (2019). Práticas de Leitura: contribuição na formação crítico-reflexiva do aluno. Research, Society and Development, 8(3).

Iser, W. (1999). O ato da leitura: uma teoria do efeito estético - vol. 2 / Wolfgang Iser, tradução de Johannes Kretschmer. (34a ed.)

Kämpf, C. (2011). A geração Z e o papel das tecnologias digitais na construção do pensamento. ComCiência Online version, 131, 4.

Lopes, L. G. (2012). A lua Castelhana, de Maria da Graça. http://textostelona.blogspot.com/2012/10/a-lua-castelhana-de-maria-dagraca.html.

Machiavelli, M. (2017). A leitura de adolescentes: dados de um estudo exploratório. Intercom - Sociedade Brasileira de Estudos Interdisciplinares da Comunicação $40^{\circ}$ Congresso Brasileiro De Ciências Da Comunicação. http://portalintercom.org.br/anais/nacional2017/resumos/R12-2127-1.pdf .

Marastoni, J. (2014). Múltiplas competências para os profissionais da educação / Josemary Marastoni. IESDE BRASIL S/A.

Marroquim, A. R. de A. \& Silva, J. D. da. (2020). Oficina com histórias em quadrinhos para alunos do sexto ano do ensino fundamental: linguagem imagética na formação de leitores. Research, Society and Development, 9(7).

Pereira, A. S., Shitsuka, D. M., Parreira, F. J., \& Shitsuka, R. (2018). Metodologia da pesquisa científica. UAB/NTE/UFSM. : https://repositorio.ufsm.br/bitstream/handle/1/15824/Lic_Computacao_Metodologia-Pesquisa-Cientifica.pdf?sequence=1 .

Santos, P. R. dos, Barbosa, D. N. F., Silva, C. R. da. \& Barbosa, J. L. V. (2019). Promovendo o desenvolvimento linguístico e o raciocínio lógico em práticas de letramento com uso de recursos tecnológicos. Revista Novas Tecnologias na Educação-Renote, 17(3).

Santos, R. da S., Carvalho, C. F. \& Ferreira, S. G. (2017). A Literatura e o Viver: o mundo dos adolescentes nos livros literários. Revista Porto das Letras. 3(2).

Silva, K. de L. \& Fernandes, J. C. da C. (2020a). Metodologias Ativas e o Lúdico: possibilidades de práticas de leitura em salas de aula. Research, Society and Development, 9(7).

Silva, K. de L. \& Fernandes, J. C. da C. (2020b). O ato de ler como instrumento de emancipação humana: importância das práticas de leitura na escola. Research, Society and Development, 9(7).

Silva, O. O. da. \& Martha, A. Á. P. A. (2017). A interação na leitura em blogs e sua mediação na formação de jovens leitores. Cultura.al.gov.br. $\quad$ http://www.cultura.al.gov.br/politicas-e-acoes/sistema-estadual-de-bibliotecas-publicas/leituras-recomendadas/me diacao $\% 20$ da\%201 itura\%20e\%20jovens\%20leitores.pdf .

Turci, V. F. \& Pacífico, S. M. R. (2019). Argumentação e autoria de adolescentes booktubers: interfaces entre a sala de aula e o ambiente virtual. Revista Eletrônica de Estudos Integrados em Discurso e Argumentação 1(19), 121-139. 